\title{
A Study of Clinico-Histopathological Correlation of Leprosy in A Tertiary Care Hospital, KIMS, Hubballi, Karnataka
}

\author{
Sindhushree $N^{*}$ and Sunita S Vernekar
}

Department of Pathology, Karnataka Institute of Medical Sciences, Karnataka, India

\begin{abstract}
Background: Leprosy is a chronic infectious disease affecting mainly cutaneous and peripheral nervous system. Histopathology provides confirmatory information for suspected cases which can be missed in clinical practice or epidemiological studies and helps in exact typing. This study was conducted to know the correlation between clinical and histopathological diagnosis of Leprosy.

Methods: This was both a retrospective study and prospective study,undertaken in the Department of Pathology, Karnataka Institute of Medical Sciences, Hubballi, over a period of 42 months from January 2013 to June 2016. Punch biopsies were taken from clinically diagnosed, clinically suspected cases of leprosy, relapse cases and lepra reactions and histopathological examinations were carried upon.

Results: A total of 280 patients were studied. Of them 193 patients $(68.92 \%)$ were males and rest $87(31.08 \%)$ patients were females. The maximum incidence was seen in the age group of 21-40yrs with 127cases (45.36\%).Maximum number of patient both clinically and histologically belonged to Borderlinetuberculoid leprosy.Clinical and histopathological correlation was seen in 61 cases (33.70\%).

Conclusion: Correlation of clinical and histopathological features along with bacteriological index is more useful for accurate typing of leprosy than considering single parameter alone.
\end{abstract}

\section{Keywords: Histopathology; Leprosy; Granuloma;Skin Biopsy.}

\section{Introduction}

Leprosy (Hansen's disease), caused by Mycobacterium leprae, is a chronic infectious disease with a predilection for the skin and nerves. ${ }^{1}$ Clinical hallmark of leprosy consists of following three characteristic signs: hypo pigmented or erythematous skin patches with definite loss of sensation, thickened peripheral nerves and acid fast bacilli on skin smear or biopsy material. ${ }^{1}$ Its a disease mainly affecting the developing world, affecting areas of Asia, Africa, Latin America and the Pacific region. India, China, Myanmar, Indonesia, Brazil, Nigeria and Nepal account for more than $80 \%$ of the worldwide cases. ${ }^{2}$ It is one of the leading causes of physical disabilities which contributes to intense social stigma resulting in discrimination of patients and their families. ${ }^{3}$

The Clinical classification describes only the gross appearances of the lesions, while the criteria used in the histopathological classification are well defined, precise and also take into account the immunological manifestations which enable it to successfully bridge the pitfalls in leprosy diagnosis. Suspicious cases which can be missed in clinical practice and epidemiological studies, can be confirmed histopathologically which helps in exact typing. Histology also gives indication of progression and regression of disease under treatment. ${ }^{4,7}$

Precise criteria for histological typing of leprosy was laid down by Ridley and Jopling. However, results of different studies have not been uniform and noted disparity between the clinical and histological diagnosis. Due to the stigma of leprosy in humans which includes potential neural damage and consequent disabilities, correct histopathological diagnosis is mandatory. ${ }^{5}$ The aim of this study was to correlate histopathological diagnosis of skin biopsies with clinical diagnosis of leprosy.

\section{Methods}

The present study was both a retrospective and prospective study, undertaken in the Department of Pathology, Karnataka Institute of Medical Sciences, Hubballi, over a period of 42 months from January 2013 to June 2016. Inclusion criteria were clinically diagnosed and clinically suspected new cases of leprosy, cases of relapse and lepra reactions. Exclusion criteria included patients who were not clinically diagnosed as leprosy.

Punch biopsies were taken and stained by HaematoxylinEosin (HE) and Fite Faraco stain. A brief clinical history, examination findings indicating signs and symptoms of the skin lesions and provisional clinical diagnosis were collected. Clinical classifications of leprosy done by dermatologist were noted. Histopathological classification of leprosy was done according to Ridley and Jopling classification and subsequent clinicopathological correlation was done. Statistical analysis is done using range, frequency, percentage. 


\section{Results}

Total 280 patients were enrolled out of which 193 were males $(68.92 \%)$ and $87(31.08 \%)$ were females with a male to female ratio of $2.2: 1$. In the present study, age range of patients was between 4-80 yrs. The maximum incidence was seen in the age group of 21-40 yrs with 127 cases (45.36\%) followed by 41-60 yrs with 72 cases $(25.71 \%)$. The lowest incidence was seen in 61-80yrs with 22 cases $(7.86 \%)$ as shown in Table 1.

The most common clinical type, Borderline tuberculoid (BT) leprosy, was seen in 95 cases (33.93\%); the remaining types, in descending order, being: Not classified in 58 $(20.71 \%)$, Relapse in $41(14.64 \%)$, Type 2 reaction in $20(7.14 \%)$, BL and LL in $16(5.71 \%)$, BB in $12(4.30 \%)$, TT in $8(2.86 \%)$, HL in $7(2.50 \%)$, IL in $4(1.43 \%)$ and Type 1 in $3(1.07 \%)$ as shown in Table 2.

Histopathologically, BT $(92 ; 32.85 \%)$ leprosy outnumbered the other types: IL $(78 ; 27.85 \%)$, TT $(32 ; 11.42 \%)$, BL $(11 ; 3.93 \%)$, LL $(10 ; 3.57 \%)$, Type 2 reaction $(8 ; 2.86 \%)$,
HL $(5 ; 1.79 \%)$ and BB \& Type 1 reaction $(1 ; 0.35 \%)$. No evidence of leprosy was seen in 39 cases $(13.94 \%)$ and inadequate biopsy in 3 cases (1.09\%) as shown in Table 3 . Among 9 cases of5 lepra reactions, 1 was diagnosed as Type 1 reaction with BT features and 8 cases were diagnosed as Type 2 reaction of which 2 cases showed features of BL type and 6 cases showed features of LL type. FF stain was negative in 186 cases and positive in 52 cases.

Histopathological features of leprosy were observed only in 238 biopsies out of 280 cases. Cases which are not classified clinically and relapse cases were excluded from clinico-histopathological correlation, so total cases of 181 were considered for clinicopathological correlation. Maximum clinico-histopathological correlation was seen in IL (100\%) followed by HL (57.14\%), BT (37.89\%), LL \& Type 1 reaction $(33.33 \%)$, Type 2 reaction $(31.57 \%)$, $\mathrm{TT}(25 \%), \mathrm{BL}(12.50 \%)$ and minimum in BB $(8.33 \%)$. Overall concordance of diagnosis was seen in 61 cases $(33.70 \%)$ in present study as shown in Table 4.

Table 1: Age wise and Sex wise distribution .

\begin{tabular}{|c|c|c|c|}
\hline Age in yrs & Male & Female & Male + Female(\%) \\
\hline$<20$ & $34(17.62 \%)$ & $25(28.74 \%)$ & $59(21.07 \%)$ \\
\hline $21-40$ & $88(45.60 \%)$ & $39(44.83 \%)$ & $127(45.36 \%)$ \\
\hline $41-60$ & $51(26.42 \%)$ & $21(24.14 \%)$ & $72(25.71 \%)$ \\
\hline $61-80$ & $20(10.36 \%)$ & $2(2.30 \%)$ & $22(7.86 \%)$ \\
\hline Total & $\mathbf{1 9 3 ( 6 8 . 9 2 \% )}$ & $\mathbf{8 7 ( 3 1 . 0 8 \% )}$ & $\mathbf{2 8 0 ( 1 0 0 . 0 0 \% )}$ \\
\hline
\end{tabular}

Table 2: Clinical types of leprosy.

\begin{tabular}{|c|c|c|}
\hline Types & No of cases & Overall percent \\
\hline IL & 4 & 2.43 \\
\hline TT & 8 & 33.93 \\
\hline BT & 95 & 4.30 \\
\hline BB & 12 & 5.71 \\
\hline BL & 16 & 5.71 \\
\hline LL & 16 & 2.50 \\
\hline HL & 7 & 20.71 \\
\hline NC & 58 & 14.64 \\
\hline RP & 41 & 1.07 \\
\hline TYPE 1 & 3 & 7.14 \\
\hline TYPE 2 & 20 & 100.00 \\
\hline Total & 280 & \\
\hline
\end{tabular}

(NC- Not classified, RP-Relapse) 
Table 3: Histological types of leprosy.

\begin{tabular}{|c|c|c|}
\hline Types & No of cases & Overall percent \\
\hline IL & 78 & 11.42 \\
\hline TT & 32 & 32.85 \\
\hline BT & 92 & 0.35 \\
\hline BB & 1 & 3.93 \\
\hline BL & 11 & 3.57 \\
\hline LL & 10 & 1.79 \\
\hline HL & 5 & 0.35 \\
\hline TYPE 1 & 1 & 2.86 \\
\hline TYPE 2 & 8 & 13.94 \\
\hline NE & 39 & 1.09 \\
\hline IB & 3 & 100.00 \\
\hline Total & 280 & \\
\hline
\end{tabular}

(NE- No evidence of leprosy, IB-Inadequate biopsy)

Table 4: Clinico-pathological correlation.

\begin{tabular}{|c|c|c|c|c|c|c|c|c|c|c|c|c|c|}
\hline \multirow{2}{*}{$\begin{array}{l}\text { Clinical } \\
\text { diagnosis }\end{array}$} & \multicolumn{11}{|c|}{ Histopathological diagnosis } & \multirow{2}{*}{$\begin{array}{c}\text { Agreement } \\
(\%)\end{array}$} & \multirow{2}{*}{$\begin{array}{c}\text { Disagreement } \\
(\%)\end{array}$} \\
\hline & IL & TT & BT & BB & BL & LL & HL & TYPE 1 & TYPE 2 & NE & IB & & \\
\hline $\mathrm{IL}(4)$ & 4 & 0 & 0 & 0 & 0 & 0 & 0 & 0 & 0 & 0 & 0 & 100 & - \\
\hline $\mathrm{TT}(8)$ & 2 & 2 & 1 & 0 & 0 & 0 & 0 & 0 & 0 & 3 & 0 & 25 & 75 \\
\hline BT(95) & 34 & 15 & 36 & 0 & 2 & 0 & 0 & 0 & 0 & 8 & 0 & 37.89 & 62.11 \\
\hline $\mathrm{BB}(12)$ & 2 & 1 & 5 & 1 & 0 & 0 & 0 & 0 & 1 & 2 & 0 & 8.33 & 91.67 \\
\hline $\mathrm{BL}(16)$ & 4 & 0 & 8 & 0 & 2 & 0 & 0 & 0 & 0 & 2 & 0 & 12.5 & 87.5 \\
\hline $\mathrm{LL}(16)$ & 1 & 1 & 4 & 0 & 2 & 5 & 1 & 0 & 0 & 1 & 1 & 33.33 & 66.67 \\
\hline $\mathrm{HL}(7)$ & 0 & 0 & 0 & 0 & 0 & 3 & 4 & 0 & 0 & 0 & 0 & 57.14 & 42.86 \\
\hline TYPE 1(3) & 1 & 0 & 1 & 0 & 0 & 0 & 0 & 1 & 0 & 0 & 0 & 33.33 & 66.67 \\
\hline TYPE 2(20) & 1 & 2 & 5 & 0 & 3 & 1 & 0 & 0 & 6 & 1 & 1 & 31.57 & 68.43 \\
\hline Total (181) & 49 & 21 & 60 & 1 & 9 & 9 & 5 & 1 & 7 & 17 & 2 & 33.70 & 66.30 \\
\hline
\end{tabular}

Table 5 : Comparison of Clinical types.

\begin{tabular}{|c|c|c|c|c|c|}
\hline Types & $\begin{array}{c}\text { Ankur et al. }{ }^{9} \\
(423)\end{array}$ & Veena et al. ${ }^{3}(200)$ & $\begin{array}{c}\text { Bijjaragi et al. }{ }^{14} \\
(171)\end{array}$ & $\begin{array}{c}\text { Shivaswamy et } \\
\text { al. }{ }^{11}(182)\end{array}$ & $\begin{array}{l}\text { Present study } \\
\text { (280) }\end{array}$ \\
\hline IL & $7.32 \%$ & $7.5 \%$ & $3.5 \%$ & $15.3 \%$ & $1.43 \%$ \\
\hline TT & $15.60 \%$ & $1.5 \%$ & $9.35 \%$ & $17.5 \%$ & $2.86 \%$ \\
\hline BT & $13.71 \%$ & $72.5 \%$ & $47.95 \%$ & $38.4 \%$ & $33.93 \%$ \\
\hline $\mathrm{BB}$ & $17.49 \%$ & $2.5 \%$ & $3.5 \%$ & $2.7 \%$ & $4.30 \%$ \\
\hline $\mathrm{BL}$ & $14.42 \%$ & $10.5 \%$ & $20.46 \%$ & $13.1 \%$ & $5.71 \%$ \\
\hline LL & $9.92 \%$ & $5.5 \%$ & $15.20 \%$ & $12.6 \%$ & $5.71 \%$ \\
\hline $\mathrm{HL}$ & $1.89 \%$ & - & - & - & $2.50 \%$ \\
\hline $\mathrm{NC}$ & $19.62 \%$ & - & - & - & $20.71 \%$ \\
\hline $\mathrm{RP}$ & - & - & - & - & $14.64 \%$ \\
\hline Type 1 & - & - & - & - & $1.07 \%$ \\
\hline Type 2 & - & - & - & - & $7.14 \%$ \\
\hline
\end{tabular}


Table 6: Comparison of Histopathological types.

\begin{tabular}{|c|c|c|c|c|c|}
\hline Types & $\begin{array}{l}\text { Veena et al. }{ }^{3} \\
(200)\end{array}$ & $\begin{array}{c}\text { Anuja et al. }{ }^{4} \\
(270)\end{array}$ & $\begin{array}{c}\text { Bijjaragi et al. }{ }^{14} \\
(171)\end{array}$ & $\begin{array}{c}\text { Shivaswamy et } \\
\text { al. }{ }^{11}(182)\end{array}$ & $\begin{array}{l}\text { Present study } \\
\text { (280) }\end{array}$ \\
\hline IL & $7.50 \%$ & $20.00 \%$ & $6.43 \%$ & $12.08 \%$ & $27.85 \%$ \\
\hline TT & $1.00 \%$ & $7.41 \%$ & $12.86 \%$ & $13.73 \%$ & $11.42 \%$ \\
\hline BT & $71.00 \%$ & $32.22 \%$ & $38.01 \%$ & $29.12 \%$ & $32.85 \%$ \\
\hline BB & $1.50 \%$ & $16.67 \%$ & $16.37 \%$ & $1.09 \%$ & $0.35 \%$ \\
\hline $\mathrm{BL}$ & $10.50 \%$ & $5.93 \%$ & $10.52 \%$ & $8.24 \%$ & $3.93 \%$ \\
\hline $\mathrm{LL}$ & $5.50 \%$ & $9.26 \%$ & $15.78 \%$ & $10.43 \%$ & $3.57 \%$ \\
\hline $\mathrm{HL}$ & - & - & - & - & $1.79 \%$ \\
\hline Type 1 & $2 \%$ & $0.37 \%$ & - & - & $0.35 \%$ \\
\hline Type 2 & $1.00 \%$ & $1.11 \%$ & - & - & $2.86 \%$ \\
\hline $\mathrm{NE}$ & - & $3.33 \%$ & - & $25.27 \%$ & $13.94 \%$ \\
\hline IB & - & $3.7 \%$ & - & - & $1.09 \%$ \\
\hline
\end{tabular}

Table 7: Comparative study of clinicopathologic correlative diagnosis by different study groups.

\begin{tabular}{|c|c|c|c|c|c|}
\hline Types & $\begin{array}{c}\text { Veena et al. }{ }^{3} \\
(200)\end{array}$ & $\begin{array}{c}\text { Anuja et al. }{ }^{4} \\
(270)\end{array}$ & $\begin{array}{c}\text { Bijjaragi et al. }{ }^{14} \\
(171)\end{array}$ & $\begin{array}{l}\text { Shivaswamy et } \\
\text { al. }{ }^{11}(182)\end{array}$ & $\begin{array}{c}\text { Present } \\
\text { Study(181) }\end{array}$ \\
\hline $\mathrm{IL}$ & $100 \%$ & $100 \%$ & $66.7 \%$ & $50 \%$ & $100 \%$ \\
\hline TT & - & $47.37 \%$ & $75 \%$ & $56 \%$ & $25 \%$ \\
\hline BT & $89.13 \%$ & $53.01 \%$ & $57.3 \%$ & $64.1 \%$ & $37.89 \%$ \\
\hline $\mathrm{BB}$ & $50 \%$ & $37.35 \%$ & $16.7 \%$ & $50 \%$ & $8.33 \%$ \\
\hline $\mathrm{BL}$ & $35.1 \%$ & $58.82 \%$ & $40 \%$ & $73.3 \%$ & $12.50 \%$ \\
\hline LL & $50 \%$ & $75.86 \%$ & $76.9 \%$ & $84.2 \%$ & $33.33 \%$ \\
\hline $\mathrm{HL}$ & - & - & - & - & $57.14 \%$ \\
\hline Type 1 & - & - & - & - & $33.33 \%$ \\
\hline Type 2 & - & - & - & - & $31.57 \%$ \\
\hline Total & $75 \%$ & $53.44 \%$ & $57.3 \%$ & $74.7 \%$ & $33.70 \%$ \\
\hline
\end{tabular}

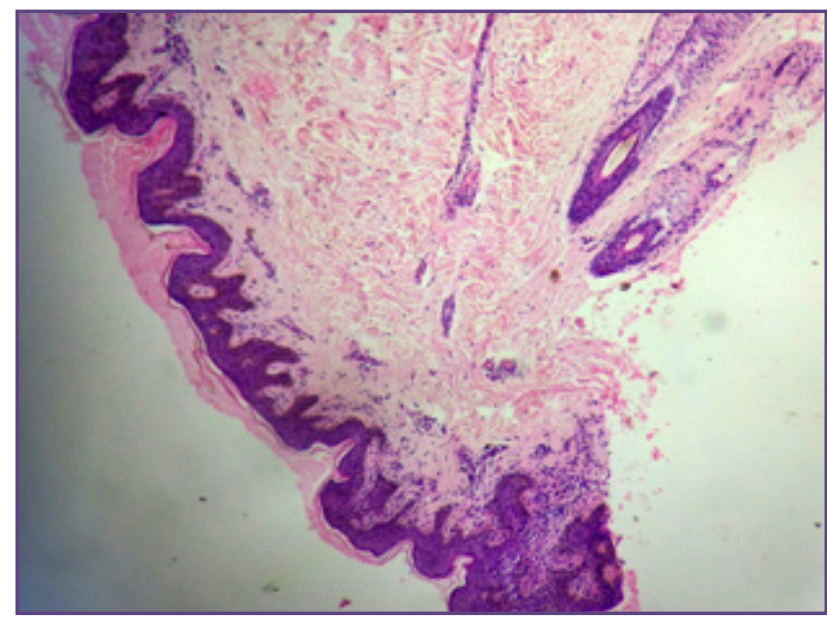

Fig. 1: Indeterminate leprosy. Slight pandermal lymphocytic inflammation \& absent grenz zone. (H\&E

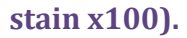

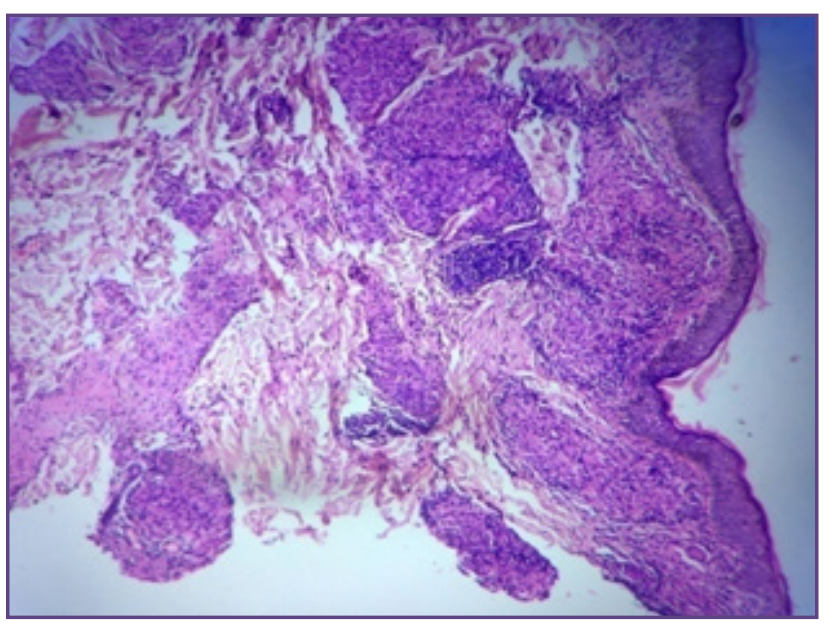

Fig. 2: Tuberculoid leprosy.Section showing epithelioid granulomas with lymphocytic infiltrates and absent grenz zone. (H\&E stain x100). 


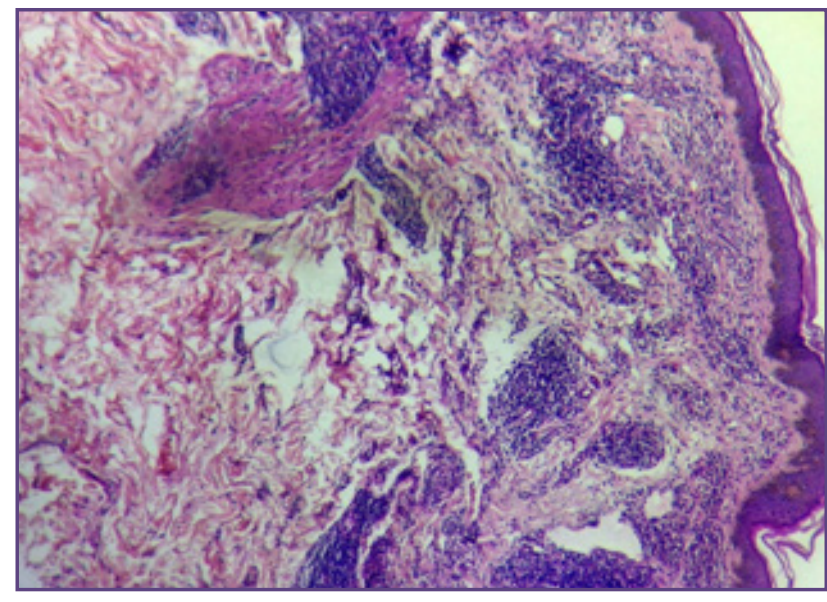

Fig. 3: Borderline Tuberculoid leprosy. Section showing epithelioid granulomas with clear grenz zone. (H\&Estainx100).

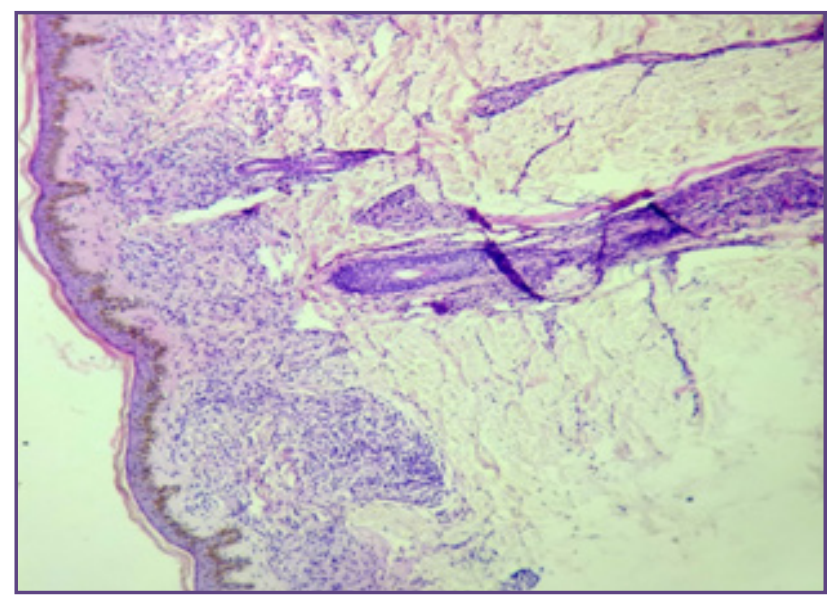

Fig. 5: Borderline Lepromatous leprosy showing subepidermal lymphohistiocyticinfiltrates admixed with few foamy cells.(H\&E stainx1000.

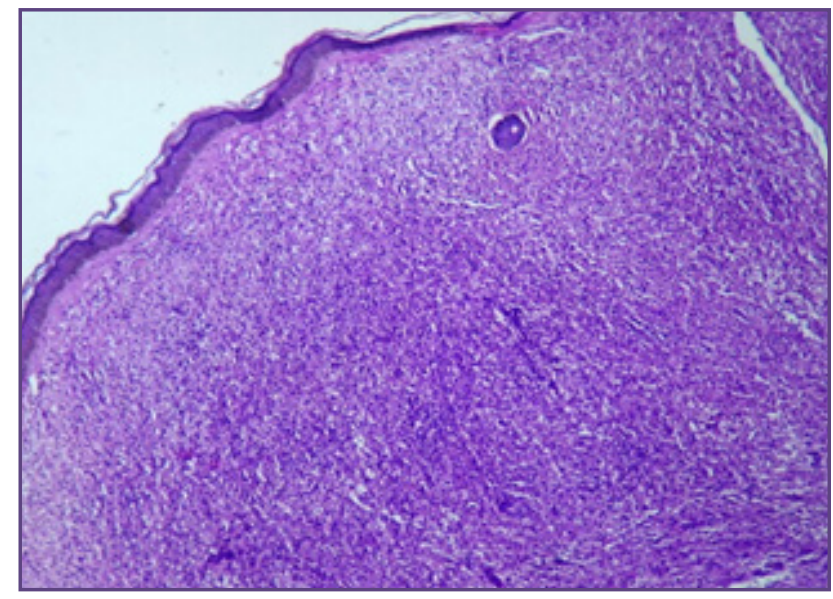

Fig. 7: Histoid leprosy. Section showing spindle shaped cells arranged in fascicles.(H\&E stain x100).

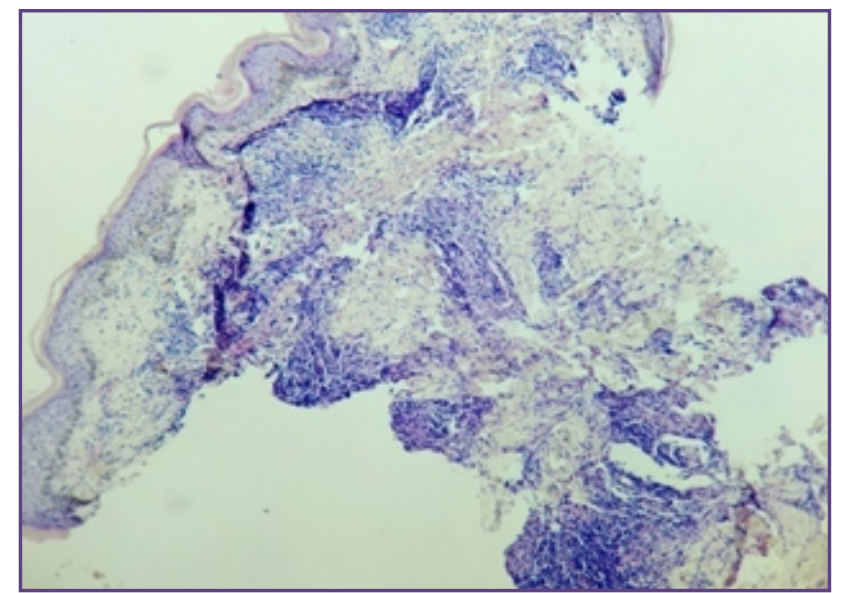

Fig. 4: Midborderline leprosy. Section showing ill formed granulomas with scattered lymphocytes. (H\&Estainx100).

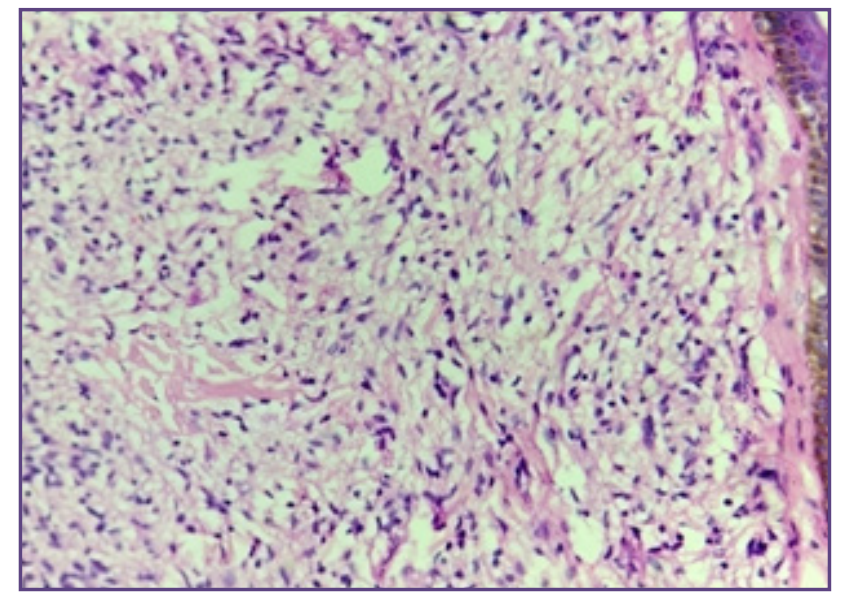

Fig. 6: Lepromatous leprosy. Section showing atrophic epidermis,grenzzone and nodular aggregates of foamy cells.(H\&Estainx4000.

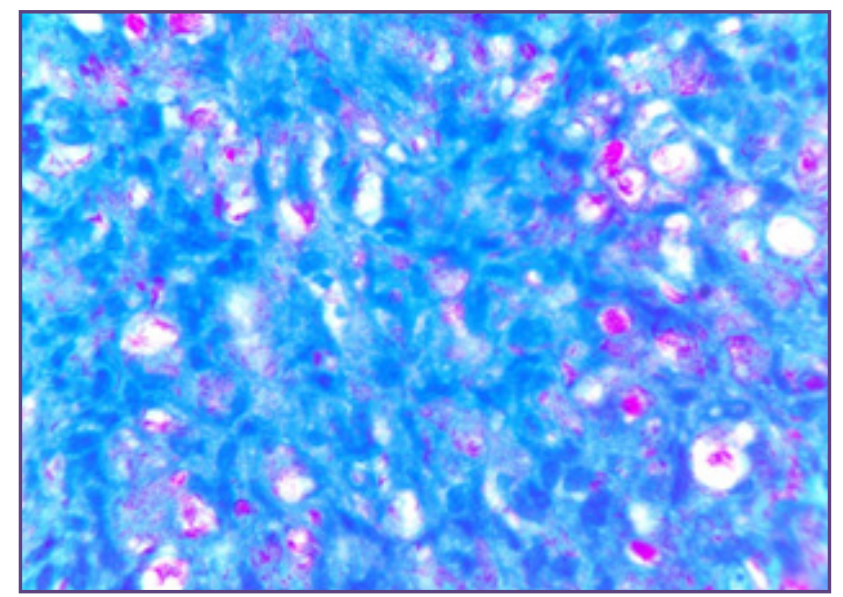

Fig. 8: Histoid leprosy. Acid fast bacilli in clusters and globi. (Modified Fite-Faracox1000). 


\section{Discussion}

In the present study, Ridley-Jopling classification was used to classify leprosy histopathologically in all cases. Indeterminate and histoid types of leprosy were also included for analysis.

Leprosy is known to occur at all ages, ranging from early infancy to very advanced age. ${ }^{8}$ Age of patients ranged from 4 to 80 years, majority $(127 ; 45.36 \%)$ belonged to $21-40$ years of age which was similar to the observations made in the other studies such as Kumar et $\mathrm{al}^{9}$ and Mathur et $\mathrm{al}^{10}$.

Although leprosy affects both the sexes, in most parts of the world males are affected more than females at a ratio of $2: 1 .^{12}$ In concurrence, the majority of the patients in this study were males $(68.92 \%)$ than females $(31.08 \%)$. The same observation was confirmed by various other authors. Male to female ratio observed in this study was 2.2:1 which is nearly similar to that observed in other studies like Kumar et $\mathrm{al}^{9}$, Shivamurthy et $\mathrm{al}^{3}$ and Shivaswamy et al ${ }^{11 .}$

BT leprosy, the most common clinical type seen in 95 $(33.93 \%)$ of our study patients, was also recorded to be the most common in the studies by Shivamurthy et al. ${ }^{3}$ (72.5\%), Bijjaragi et al. ${ }^{14}(47.9 \%)$ and Shivaswamy et al. ${ }^{11}(38.4 \%)$. Not classified (type of leprosy couldn't be specified) group were also included by other studies like Kumar et al. ${ }^{9}$ which is similar to this study as shown in Table 5 .

In this study 39(13.94\%) cases showed no features of leprosy and 3(1.09\%) cases had inadequate biopsy. The pattern of leprosy in this study showed predominance of BT $(32.85 \%)$ followed by IL (27.85\%). Similar findings were seen in other studies by Anuja et al. ${ }^{4}$ and Shivaswamy et al. ${ }^{11}$. Borderline group constituted the major spectrum (37.14\%) which included BT, BB, BL and these were similar to the findings in other studies like Veena et al. ${ }^{3}$ and Bijjaragi et al. ${ }^{14}$. Least common type in this study was Type 1 reaction and BB type $(0.35 \%)$, which is similar to the studies by Sharma et al. ${ }^{4}$ and Shivaswamy et al.$^{11}$ as shown in Table 6.

Immunological instability in these borderline cases makes them move in either direction along the borderline spectrum. With treatment, they move toward tuberculoid pole (upgrading), and without treatment or lowered immune status, they move toward lepromatous pole (downgrading). ${ }^{15}$ Increased awareness of the people to leprosy because of many national programmes makes them to present at an earlier stage to leprosy clinics, which may contribute to increased number of borderline group of leprosy. ${ }^{3}$
In present study, hypopigmented patches were the commonest clinical feature observed in 164 cases $(58.57 \%)$ followed by nerve thickening in 113 cases (40.35\%), erythematous patches in 110 cases $(39.28 \%)$ and loss of sensation in 92 cases(32.85\%). Studies by Shivamurthy et al. ${ }^{3}$ and Rizvi et al. ${ }^{13}$ found anaesthesia as the commonest clinical feature followed by nerve thickening and hypopigmented patches. Nadia et al. ${ }^{16}$ found hypopigmented patches and loss of sensation as the commonest clinical finding followed by erythematous patches. Since skin and nerves are the common habitats of lepra bacillus, the signs and symptoms related to them are common.

280 skin biopsies in the present study were classified according to histopathological features and subsequently correlated with the clinical features in order to arrive at an accurate diagnosis. Histopathological features of leprosy were observed only in 238 biopsies out of 280 cases. Cases which are not classified clinically and relapse cases were excluded from clinico-histopathological correlation, so total cases of 181 were considered for clinicopathological correlation. Overall clinico-histopathological agreement was seen in 61(33.70\%) cases and disagreement in $120(66.30 \%)$ cases, which in the earlier Indian studies had clinico-histopathological agreement ranging from $53 \%$ to $75 \% .{ }^{3,4,11,14}$ as shown in Table 7.

In this study, highest $(100.00 \%)$ clinico-histopathological agreement was found in Indetermediate Leprosy (IL) and highest (91.67\%) disagreement was found in Midborderline (BB) leprosy which were similar to the findings in other studies by Sharma et al. ${ }^{4}$ and Shivamurthy et al. ${ }^{3}$ But in contrary to our result, study by Bijjaragi et al. ${ }^{14}$ and Shivaswamy et al. ${ }^{11}$ had highest clinico-histopathological correlation in LL and highest disagreement in BB and IL type of leprosy (Table 7). Manandhar et al. ${ }^{5}$ found highest agreement in BT leprosy and highest disagreement in TT leprosy.

The variation in different studies may be due to different criteria used to select the cases and difference in number of cases of each type. Various factors also influence the histopathological diagnosis such as differences in sample size, choice of the biopsy site, age of the lesion, immunological and treatment status of the patient at the time of biopsy. In some studies, cases with only macular lesions were selected. ${ }^{17}$ This study consisted of cases with all types of lesions such as macules, papules, nodules, etc. The present study also included relapse cases, histoid leprosy and lepra reactions which are similar to other studies. ${ }^{3,6,9,18}$ 
The disparity between clinical and histological observations was anticipated because the parameters used for the histopathologic classification are well-defined, precise and also take into account the immunologic response of the tissue, while the clinical classification gives recognition only to the gross appearances of the lesions which is due to the underlying pathological change. ${ }^{9}$ Moreover, a sizable proportion of leprosy cases $(\mathrm{BT}+\mathrm{BB}+\mathrm{BL})$ are in a continuously changing immunological spectrum and histological classification gives a better indication for any recent shift of a case position in the spectrum..$^{4,7}$

In some early cases, clinical signs and symptoms may precede the presently known characteristic tissue changes, or vice versa. If a biopsy is taken at an early stage, there is likely to be discordance between the clinical and histopathologic observations. As disparity depends upon the lesion biopsied at the time of study, biopsy from the lesion which is morphologically suggestive of clinical diagnosis, serial biopsies from the same lesion, or from paired lesions, should be studied for a better clinicohistopathological correlation. ${ }^{4}$

Various other factors influence the histopathological diagnosis, including different criteria used to select the cases, number of cases of each type, age of the lesion, nature and depth of the biopsy, quality of the section, number of acid-fast stained sections examined, immunological and treatment status of the patient at the time of diagnosis. ${ }^{5}$

A study by Cortes and Rodriguez, leprosy was confirmed by histopathology in 119 cases (57.5 percent) out of 207 biopsies and in study by McDougall et al. ${ }^{21}$, only $52 \%$ (354) of the biopsies out of 684 showed definite evidence of leprosy on histopathological examination. The discrepancy is due to clinical over diagnosis of leprosy and misinterpretation of many skin conditions presenting with hypopigmented patch as leprosy. The disparity could be due to the occurrence of reaction or due to type and site of lesion from where biopsy was taken. ${ }^{5}$ Selection of the site for biopsy plays an important role in the histopathological diagnosis since clinically dissimilar lesions biopsied from the same patient can show different types of histopathology. ${ }^{19}$

The histopathological features in leprosy indicate the accurate tissue response while the clinical features indicate only the gross morphology of the lesions caused by the underlying pathology. Since tissue response varies in the disease spectrum due to variability of cell mediated immunity, it is logical to expect some disparity between clinical and histopathological features (Kar et al.). ${ }^{20}$
Histopathological classification has the advantage over the clinical classification that it gives a better indication of any recent shifts in the patients position in the spectrum (Ridley DS). ${ }^{14}$

\section{Conclusion}

Study of different types of leprosy lesions contribute a great deal in understanding the disease. A gold standard method for the diagnosis of type of leprosy cannot be established since the tissue response differs depending on the immunity of the host. However, biopsy of the skin lesion is a useful tool in confirming the clinical diagnosis and hence should be carried out for all suspected cases of leprosy to determine the spectrum of the disease and initiate multidrug therapy as per the treatment category. Correlation of clinical and histopathological features along with bacteriological index is more useful for accurate typing of leprosy than considering single parameter alone. As there is overlap in histopathologic features of different types of leprosy, morphology alone is not specific, thus adequate clinical data can help in good clinicopathologic correlation.

\section{Acknowledgement}

Author thankful to Karnataka Institute of Medical Sciences, Rajiv Gandhi University of Health Sciences, Hubballi, 580021.

\section{References}

1. Bhat RM, Prakash C. 2012. Leprosy: An Overview of Pathophysiology. Interdisciplinary Perspectives on Infectious Diseases 2012:1-6.

2. Gelber RH. Leprosy. In: Longo DL, Fauci AS, Kasper DL, Hauser SL, Jameson JL, Loscalzo J, eds. Harisson's principles of internal medicine.18th ed. New York: McGraw Hill, 2012:1359-67.

3. Shivamurthy V, Gurubasavaraj H, Shashikala PS, Kumar P. Histomorphological study of leprosy. Afr J Med Health Sci 2013;12(2):68-73.

4. Sharma A, Sharma RK, Goswsami KC, Bardwaj S. ClinicoHistopathological Correlation in Leprosy. JK Science 2008;10(3): 120-123.

5. Manandhar U, Adhikari RC, Sayami G. Clinicohistopathological correlation of skin biopsies in leprosy. Journal of pathology of Nepal 2013; 3: 452-458.

6. Dyavannanavar V, Belagatti S,Shashikant.Clinical and Histopathological Correlation in Leprosy: A Tertiary care hospital based study. International Journal of Healthcare Sciences 2015;3(1):265-269.

7. BanushreeCS,BhatRV,UdayashankarC.Clinicopathological correlation of Hansen's disease: a retrospective study of skin biopsies. Indian Journal of Pathology and Oncology 2016; 3(3): 491-495. 
8. Gillis W, Rouge B. Survey of Newly Diagnosed Leprosy Patients in Native and Foreign Residents of Japan. International Journal of Leprosy 2000; 68(2): 172-176.

9. Kumar A, Negi SR, Vaishnav K. A study of Clinicohistopathological correlation of leprosy in a tertiary care hospital in western district of Rajasthan. J Res Med Den Sci 2014; 2(3): 43-8.

10. Mathur MC, Ghimire RBK, Shrestha P, Kedia SK .Clinicohistopathological Correlation in Leprosy. Kathmandu Univ Med J 2011;36(4): 248-51.

11. K N Shivaswamy, A L Shyamprasad, T K Sumathy, C Ranganathan,Agarwal V.Clinico histopathological correlation in leprosy. Dermatology Online Journal 2012;18 (9): 1-4.

12. Kumar R, Singhasivanon P, Sherchand JB, Mahaisavariya P, Kaewkungwal J, Peerapakorn Set al.Gender difference in socio-epidemiological factors for leprosy in the most hyperendemic district of Nepal. Nepal Med Coll J 2004; 6(2): 98-105.

13. Rizvi AA, Sharma YK, Dash K,Tyagi N, Yadava R, Sadana D. An epidemiological and clinicohistopathologica lstudy of leprosy in semi-urban area under PimpriChinchwad Municipal Corporation in Pune district of Maharashtra.Med J DY Patil Univ 2015;8(5): 609-13.

14. Bijjaragi S, Kulkarni V, Suresh KK, Chatura KR and Kumar P. Correlationof clinical and histopathological classification of Leprosy in post elimination era. Indian J Lepr 2012;84 $: 271-275$
15. Premalatha P, Renuka IV, Meghana A, Devi SI, Charyulu PAVK, Sampoorna G. Utility of bacillary index in slit skin smears in correlation with clinical and histopathological alterations in hansen's disease: An attempt to revive a simple useful procedure. Ann Med HealthSci Res 2016; 6(3):181-4.

16. Nadia S, Rashmi J, Sohaib A, Rawat SDS, Thamarai NS, Meena H.Clinicopathological Correlation of Leprosy: A 4 years retrospective study from a tertiary referral centre in North India. Int J Med Res Health Sci. 2015; 4(2): 350-354.

17. Shenoi SD, Corre SK. Clinical and histopathological features in untreated macular lesions of leprosy - A study of 100 cases. Ind J Lepr 1988; 60(2): 202-5.

18. Thapa DP, Jha AK. Clinico-Histopathological Correlation in Leprosy:A Tertiary care hospital based study. Our Dermatol Online 2013; 4(3): 294-296.

19. Giridhar M, Arora G, Lajpal K and Chahal K S (2012). Clinicohistopathologicalconcordance in Leprosy - A Clinical, Histopathological and Bacteriological study of 100 cases. Indian J Lepr2012;84: 217-225

20. Kar PK, Arora PN, Ramasastry CV et al (1994). A clinicoPathological study of Macular lesions in Leprosy. Indian J Lepr. 66: 435-442.

21. McDougall AC, Ponnighaus J and Fine PE (1987). Histopathological examination of skin biopsies from an epidemiological study of leprosy in northern Malawi. Int $\mathrm{J}$ Lepr Other Mycobact Dis. 55: 88-98.

*Corresponding author:

Dr. Sindhushree N, W/O Manoj P, \#416, 10th Main, Contour road, Alanahally layout, Mysore, Karnataka- 570011 INDIA

Phone: +91 7795411141

Email: dr.sindhu.kshitij@gmail.com

Financial or other Competing Interests: None. 